\title{
Setting agenda for quality improvement in a public hospital in Nigeria using the consumers' judgement
}

\author{
D.S. Ogaji ${ }^{1}$, A.J. Etokidem ${ }^{2}$ \\ 1. Dr Daprim Ogaji, Department of Community Medicine, Niger Delta University, Amassoma, Nigeria \\ 2. Dr Aniekan Etokidem, Department of Community Medicine, University of Calabar, Calabar, Nigeria
}

\begin{abstract}
Background: The paradigm shift in the locus of control in many health systems brought about by consumerism, makes it imperative for consumers of health services to be involved in setting agenda for quality improvement.. This study sought to identify service quality gaps in a public hospital using the clients' judgement.

Methodology: Sixty-eight consenting clients attending the State House Hospital, Yenagoa, were administered an adapted version of the SERVQUAL instrument to rate their expectation before and perception after the encounter with the practice. Negative gap scores indicated that the actual service (the perceived score) was less than what was expected (the expectation score) and thus requires some form of quality improvement. Criteria having high expectation scores from the clients were also of importance to the administrators of the facility.

Result: Majority of the raters were married (71.2\%) and female (55.9\%). Significant gaps were elicited in clients' desire for up-to-date equipment for patient care (-1.15); desire to be able to trust staff (-1.06) and feel safe with hospital's employees (-1.11). All 5 dimensions showed some degree of inadequacies but none crossed the pre-set critical line. Majority of the clients showed general satisfaction with the performance of the hospital (88.4\%), a likelihood of return (76.3\%) and recommending to others (81.0\%)

Conclusion: The identification of symptoms of dysfunction in this organization through this instrument provided a starting point for the examination of underlying problems that inhibit the provision of quality service.
\end{abstract}

Keywords: Quality improvement, SERVQUAL, clients' expectation, clients' perception, quality gap, Yenagoa.

\section{INTRODUCTION}

Quality of Care is the level of performance or accomplishment that characterizes the health care provided, and its ultimate measure always depending upon value judgements on various ingredients and determinants which have been classified into measures of structure, process and outcome. ${ }^{[1]}$ Pertinent however, in any meaningful assessment of the functional quality of health service delivery are the views and feelings of the health care consumer. Functional quality refers to the manner in which the health care service is delivered to the patients who are often unable to accurately assess technical quality and therefore, functional quality is the primary determinant of patients' quality perception. ${ }^{[2],[3]}$ The current focus on consumerism and accountability in the delivery of health services is forcing hospitals to address whether (or not) patients are satisfied with the care they receive and as a result of this paradigm shift, reforms in many health systems have sought to strengthen the role of health service users and patients in ensuring accountability, particularly for quality assurance and for improving performance. ${ }^{[4],[5]}$

The utilization of patients' assessment is based on the notion that if patients are truly satisfied, they have in fact received good care. This notion carries with it a guarded validity, as many of the surveys carried out are organized around theories of human judgement, which are highly subjective. In current health care context, nonetheless, patients' evaluation is seen to have both practical and political relevance - practically long waiting times and/or unsatisfactory relationships with health care professionals are potential barriers to seeking treatment. Patient satisfaction with an apparent emphasis on the viewpoints of individual patients is a way of eliciting how responsive the health service is to the public politically and closing the identified gaps that exist between clients' expectation before service encounter and their perception of the actual services after the encounter has the potential of improving service quality as well as utilization of these services. ${ }^{[6], \text { [7] }}$

Health professionals now realise the need to demonstrate that their services are truly client-focused and that continuous performance improvement is being made through the judgement of their clients. The various reasons for assessing patient perception from the hospital's perspective, stem from the fact that patient satisfaction is considered to be a desired outcome of care at a time when the technical aspects of medicine are overtaking humanistic factors; patient perception is also predictive of future behaviour (compliance with recommended treatments); and lastly, patient perception is related to the quality of care, in interpersonal and organizational areas as well as in technical domains. ${ }^{[8], ~[9]}$ Earlier works that had been published gave credence to the benefits 
derivable from reorienting health services to being more client focused in resource-poor countries where middle level managers are under increasing pressure to identify cost-effective ways of providing services that are tailored to the legitimate expectations of the clients. ${ }^{[9],[10],{ }^{[11]}}$ These trends revealed in resource poor countries are not different from developed countries as Weisman, et al in 2000 reported that $95 \%$ of Health Maintenance Organizations in a developed health system utilized clients' views in quality improvement processes. ${ }^{[6]}$ The various elements of 'responsiveness' which describes how clients' legitimate expectations are met have been used by the World Health Organization as common indicators for comparing various health systems across the globe ${ }^{[7]}$ Consumers' perceived quality is inarguably the single most important variable influencing consumers' value perceptions and these perceptions in turn, affect consumers' intentions to purchase services.

Ratings of the quality of service delivery by patients through their perception, expectation, satisfaction amongst others thus contribute important information needed for quality improvement that may not be available by monitoring more traditional measures of performance alone. ${ }^{[6],[8],[9]}$ Various instruments that used consumer assessment in quality improvement have been developed and psychometrically tested and found suitable for various uses cutting across specialties, practice patterns and diseases. ${ }^{[12], ~[13], ~[14], ~[15], ~[16] ~}$

The SERVQUAL instrument ${ }^{[18]}$ is one of these robust instruments, suitable for eliciting gaps in service quality as perceived by the clients and it has been used to measure differences in service quality between public and private hospital in Istanbul, Turkey, ${ }^{[12]}$ and also in assessment of nursing care by post discharge patients in Turkey. ${ }^{[19]}$ The instrument had been psychometrically tested to be valid and reliable for measuring functional service quality in the hospital environment and in a variety of other service industries. ${ }^{[3]}$

This study is an attempt to use the SERVQUAL instrument to ascertain perceived gaps in the quality of service delivery in a public general practice setting using the clients' ratings.

\section{METHODOLOGY}

This is a descriptive cross-sectional study carried out in the State House Hospital - a general practice facility in Yenagoa, the capital city of Bayelsa State in Nigeria. This 19- bedded public hospital provides care to diverse patient population with about 600 outpatient visits monthly and run by 7 physicians and 19 nurses among other health professionals and ancillary staff.

Sixty-eight consenting outpatients aged 18 and above attending the State House Hospital, Yenagoa in the second week of November 2008, were administered a pretested adapted version of the SERVQUAL instrument as part of the activities of the end of year performance evaluation and future planning for the facility. A team of 4 health care providers (three doctors and one nurse) who had requisite experience in health services research were involved in the review of the content and construct of this previously validated instrument used in this study. Three Youth Corp Members who were undertaking their National Service at the Facility were trained as research assistants and provided assistance to clients in their ratings. Clients voluntarily and anonymously rated their expectations as they entered the facility.

The ratings of the expectation and perception of the client on each of the 22-quality criteria were done using a 5-point Likert scale (1, strongly disagree; 2, disagree; 3, undecided; 4, agree; 5, strongly agree) treated as intervals to allow the use of common parametric tests. Questions included both positively and negatively worded items to minimize the potential bias that occurs from clustering of responses to one side of the scale. These criteria were later grouped under five dimensions which were:

- $\quad$ Tangibles (1 -4) - Physical facilities, equipment, appearance of personnel

- Reliability (5 - 9) - Ability to perform duty dependably and accurately

- $\quad$ Responsiveness (10-13) - Willingness to help clients and provide prompt service

- Assurance (14 - 17) - competence, courtesy, credibility and security

- Empathy (18 - 22) - Access, communication, understanding of client, caring and individualized attention that the service provides to its clients.

The gap score from each criterion was calculated by subtracting the expectation score from the perception score and the average gap score for each dimension was obtained as the un-weighted gap scores for each of the indicators that constitute the dimension. A negative score (alert) indicated that the actual service (the perceived score) was less than what was expected (the expectation score) and thus requires quality improvement. A maximum allowable limit of deficiency (action) for each criteria or dimension to instigate priority action was fixed at $20 \%$ (representing a negative gap score of $\geq 1$ ). The mean gap from the 5 dimensions was also obtained as the un-weighted measure of service quality. Strong emphasis were also placed on criteria in which expectation scores by these clients were particularly high as this could influence management to decisively promote improvement actions in these areas and tailor its services more to meet the legitimate expectations of the clients. Qualitative investigations on clients' general satisfaction, likelihood of return or recommending the facility to friends/relatives with similar problems were also carried out. 
Data from this study were analysed using Epi-Info version 3.5.1 and results expressed as gaps, means, maximum, minimum values and as percentages for qualitative variables

\section{RESULTS}

The demographic characteristics of the clients showed that $55.9 \%$ were females while $44.1 \%$ were males with majority (71.2\%) being married (Table 1 ).

In all criteria, ratings made on clients' expectations before the encounter were more than what they perceived after the encounter thus, giving negative gap scores with the maximum allowable limit of deficiency were exceeded on the criteria bordering on state of the equipment in the hospital (-1.15); ability to trust (-1.06) and also feel safe (-1.11) with the staff of the hospital as shown in table 2.

Figure 1 showed that negative gaps were also elicited in all the five dimensions, but none of these gaps in the dimensions crossed the maximum allowable limit of inadequacy of $20 \%$. The tangible dimension representing the physical facilities, equipment and appearance of the personnel; and the assurance dimension which represents competence, courtesy, credibility and security) generated the highest gap requiring quality improvement. Expectations of the clients were highest in the tangible, reliability and assurance dimensions.

Figure 2 showed that only $3.3 \%$ of clients studied expressed complete dissatisfaction with the encounter, and these were all female respondents. Clients' likelihood of returning to the same facility in the event of having a similar problem was presented in figure 3 and this showed that while majority $(76.3 \%)$ would be willing to repeat their visit to this hospital in the event of having similar health condition they currently have, only $1.7 \%$ completely ruled out this possibility. In the same vein, majority $(81.0 \%)$ were willing to recommend the facility to friends and relatives while still a smaller proportion constituting $1.7 \%$ were not inclined towards recommending this facility to anyone else (Figure 4)

\section{DISCUSSION}

This study was designed to enhance our understanding of the utilization of clients' judgement in quality improvement. The instrument was able to elicit gap scores which gave valuable insights into the scope of improvement actions to be taken to get better overall quality that would meet the expectation of the clients. Deficient scores in one or more SERVQUAL criteria or dimensions usually signal the existence of a deeper underlying problem in the organization. A 5-points Likert scoring scale was used in this study, while previous studies done in Turkey used 6-points and 7-points scales to elicit difference in service quality between public and private hospital and assessing patients' satisfaction with nursing care after discharge from hospital respectively. ${ }^{[12],[19]}$

Gap seen in the state of the equipment in this facility was significant as it crossed the $20 \%$ allowable limit of deficiency. A number of factors could have accounted for this seeming gap as this public facility, like many others in its practice environment are often bereft of necessary financial and technical resources that could guarantee the acquisition, use and maintenance of modern hospital equipment.

The observed gap in the willingness of clients to trust and also feel safe with the staff of the hospital as shown in this study leaves more to be desired as this borders on lack of positive organizational culture in most of our public facilities. These low scores may also be indicative of deeper problems that centre on organization's ability to hire and retain high-quality employee, evaluate and reward service performance, or to provide adequate training ${ }^{[3]}$. Blumenthal reported that the quality of interaction between providers and patients depends on several elements in their relationships like the quality of their communication; the physician's ability to treat the patient with concern, empathy, honesty, tact and sensitivity. ${ }^{[9]}$ This deficiency can however, be mitigated by building stronger positive organizational culture and operating procedures that would improve the level of assurance of service users when doing transactions with our facilities. The expectation scores recorded in the tangibles, reliability and assurance dimensions make it imperative for the hospital's administrators to focus on these dimensions so that service delivery process can be tailored to meet the expectations of the clients.

Deficiencies observed in service quality in all criteria and dimensions studied, may not be surprising as the main goal of health care in this and many other settings appear to be the attainment of improved biophysical outcomes, with less emphasis placed on the satisfaction and value judgement by the consumers which is the focus of functional quality. Involvement of health consumers in quality improvement which has been a feature of the health system of most developed countries and had led to the provision of services that are tailored to meet the needs and acceptance of these health consumers should also be considered as a starting point in all improvement activities in our setting. 


\section{CONCLUSION}

A major contribution of the use of this instrument to the hospital was its ability to identify symptoms of deficiencies in the organization and provided a starting point for the examination of these underlying problems that inhibited the provision of quality service. Implementation of identified gaps following this assessment will inarguably lead to a health service that would be tailored to the needs, preferences and acceptability of the clients that would also promote their psychological ownership and utilization of the facility. This, to the authors should be a major goal of a community-based health care practice.

\section{ACKNOWLEDGEMENT}

The authors would like to thank Dr Tarila-Ijeh, the Practice Manager and Dr Ikuli, the Head of the quality assurance committee in the State House Hospital, Yenagoa, for their important contribution in the conduct of this study.

\section{REFERENCES}

1. Last MJ. A dictionary of epidemiology. Oxford University Press 1983; New York: 86

2. Mendoza AJ, Piechulek H, al-Sabir A. Clients' satisfaction and quality of health care in Rural Bangladesh. Bulletin of the World Health Organization 2001; 79(6):512-517.

3. Babakus E, Mangold W. Adapting the SERVQUAL scale to Hospital Services: An Empirical Investigation. Health Services Research 1992; 26(6): $767-786$.

4. Brinkerhoff D. Accountability and health systems: overview, framework and strategies. Technical Report 2003 ; 018. Available from http://www.phrproject.com [retrieved $6^{\text {th }}$ of March, 2007].

5. Ries NM, Caulfield T. Accountability in health care and legal approach. Canadian Policy Research Networks Inc 2004:1-5.

6. Weisman CS, Rich DE, Rogers J, Crawford KG, Grayson CE, Henderson JT. Gender and Patients satisfaction with primary care: turning in to women in quality measurement. Journal of Women's Health and Gender Bases Research 2000; 9:657-665.

7. World Health Organization 2000. Health systems: improving performance. The World Health Report 2000, WHO Geneva: 144.

8. Labarere J, Francois P, Auquier P, Robert C, Fourny M. Development of a French inpatient satisfaction questionnaire. International Journal for Quality in Health Care 2001; 13(2):99-108.

9. Blumenthal D. Quality of care- what is it? N Engl J Med 1996; 335(12):891-894.

10. Turris SA. Unpacking the concept of Patients satisfaction: a feminist analysis. Journal of Advanced Nursing 2005; 50(3):29398.

11. Ellis R, Whittington D. Quality assurance in health care, a handbook. London: Edward Arnold 1993: 66-183.

12. Taner T, Antony J. Comparing public and private hospital care service quality in Turkey. Leadership in Health Services 2006; 19(2):1-10.

13. Grol R, Wensing M. Patients evaluate general/family practice: the EUROPEP Instrument 2000.

14. Hikkink CF, Sixma HJ, Wigersma L, Yzermens CJ, van der Meer JT, Bindels PJ, et al. QUOTE - HIV: an instrument for assessing quality of HIV care from patients' perspective. Oual Saf Health Care 2003; 12:188-193.

15. Garret A, Bjaertnes A, Krogstad U, Gulbrandsen P. The OutPatient Experiences Questionnaire (OPEQ): data quality, reliability, and validity in patients attending 52 Norwegian hospitals. Qual Saf Health Care 2005; 14:433-437.

16. Ramsay J, Campbell JL, Schroter S, Green J, Roland M. The General Practice Assessment Survey (GPAS): test of data quality and measurement properties. Family Practice 2000; 17:372-379.

17. Meakin R, Weinman J. The 'Medical Interview Satisfaction Scale' (MISS-21) adapted for British general practice. Family Practice 2002; 19:257-263.

18. Parasuraman A, Zeithaml V, Berry L. SERVQUAL: A multiple-item scale for measuring customer perception of service quality. Journal of Retailing 1988; 64(1):12-40.

19. Uzun O. Patient satisfaction with nursing care at a university hospital in Turkey. Journ Nurs Care Qual 2001; 16(1):24-33. 
Setting agenda for quality improvement in a public hospital in Nigeria using the consumers'

judgment

Table 1: Demographic characteristics of raters

\begin{tabular}{lcc}
\hline Characteristics & Frequency $(\mathbf{n}=\mathbf{6 8})$ & Percentage \\
\hline Sex & 30 & 44.1 \\
Male & 38 & 55.9 \\
Female & & \\
Marital status & 49 & 72.1 \\
Married & 15 & 22.1 \\
Never married & 4 & 5.8 \\
Separated/divorced & & \\
\hline
\end{tabular}

Table 2: Clients' un-weighted mean perception, mean expectation and gap scores.

\begin{tabular}{llll}
\hline Statement frame & PS & ES & GS \\
\hline 1. Modern looking equipment for patient care & 3.50 & 4.65 & -1.15 \\
2. Visually appealing physical facilities & 3.59 & 4.35 & -0.76 \\
3. Well dressed and neat employees & 3.99 & 4.43 & -0.44 \\
4. Physical appearance matching services rendered & 3.51 & 4.27 & -0.76 \\
5. Keeping to appointments & 3.57 & 4.46 & -0.89 \\
6. Sincere interest in addressing clients' problems & 4.63 & 4.44 & 0.19 \\
7. Performing the services rightly the first time & 3.64 & 4.01 & -0.37 \\
8. Providing services as stipulated & 3.81 & 4.24 & -0.43 \\
9. Accuracy of clients' record keeping & 3.91 & 4.51 & -0.61 \\
10. Information on exact timing of planned services & 2.75 & 2.82 & -0.07 \\
11. Staff give prompt services & 2.77 & 2.51 & 0.26 \\
12. Staff continuous willingness to help & 1.98 & 2.86 & -0.88 \\
13. Staff continuous availability to give attention & 2.22 & 2.65 & -0.43 \\
14. Staff behaviour instilling confidence in clients & 3.64 & 4.70 & -1.06 \\
15. Feeling safe when dealing with staff & 3.84 & 4.95 & -1.11 \\
16. Consistent courtesy from staff & 4.41 & 4.41 & 0 \\
17. Staff being supported to attend to clients & 3.74 & 4.25 & -0.51 \\
18. Individual attention given by the hospital & 2.63 & 3.14 & -0.51 \\
19. Staff giving clients personal attention & 2.46 & 2.87 & -0.41 \\
20. Staff knowing what clients' needs are & 2.11 & 2.50 & -0.39 \\
21. Hospital having clients' best interest at heart & 2.11 & 2.28 & -0.17 \\
22. Convenience of operating hours & 2.25 & 2.47 & -0.22 \\
\hline
\end{tabular}

\section{PS (Perception score), ES (Expectation score), GS (Gap score)}

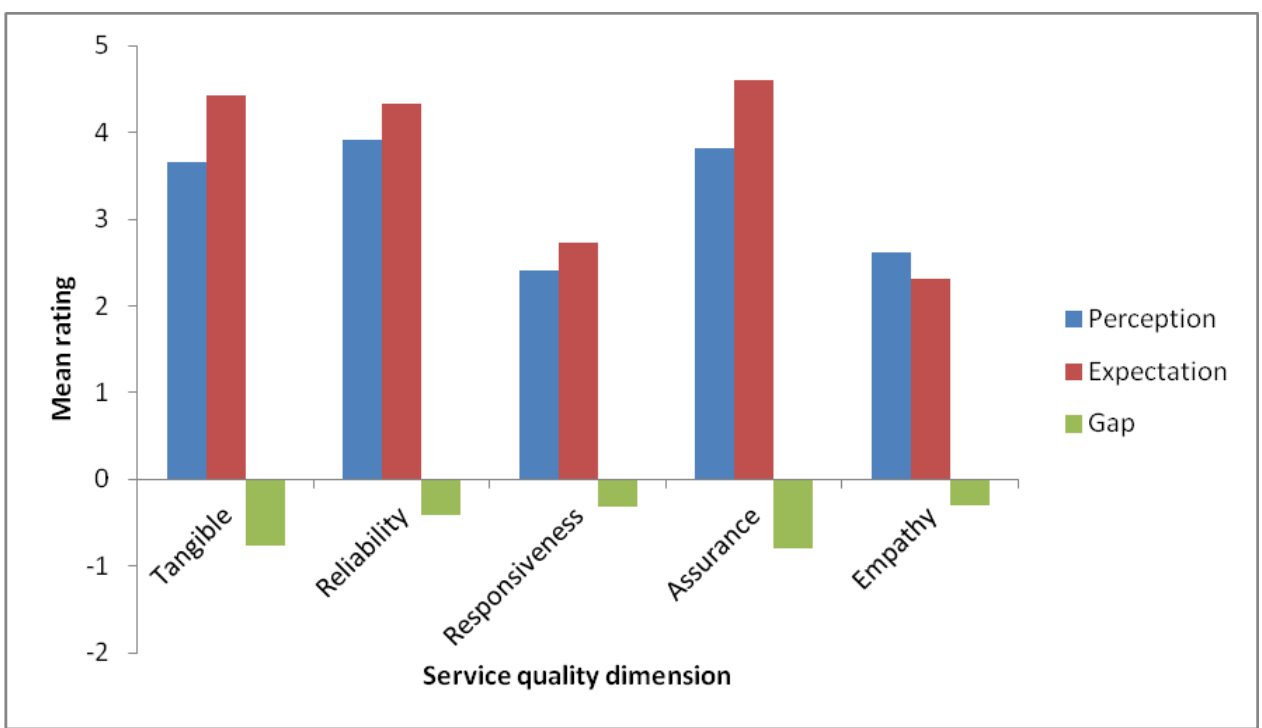

Figure 1: Chart showing raters' perceptions, expectation and gap along the five dimension of service quality

WWw.iosrjournals.org 
Setting agenda for quality improvement in a public hospital in Nigeria using the consumers'

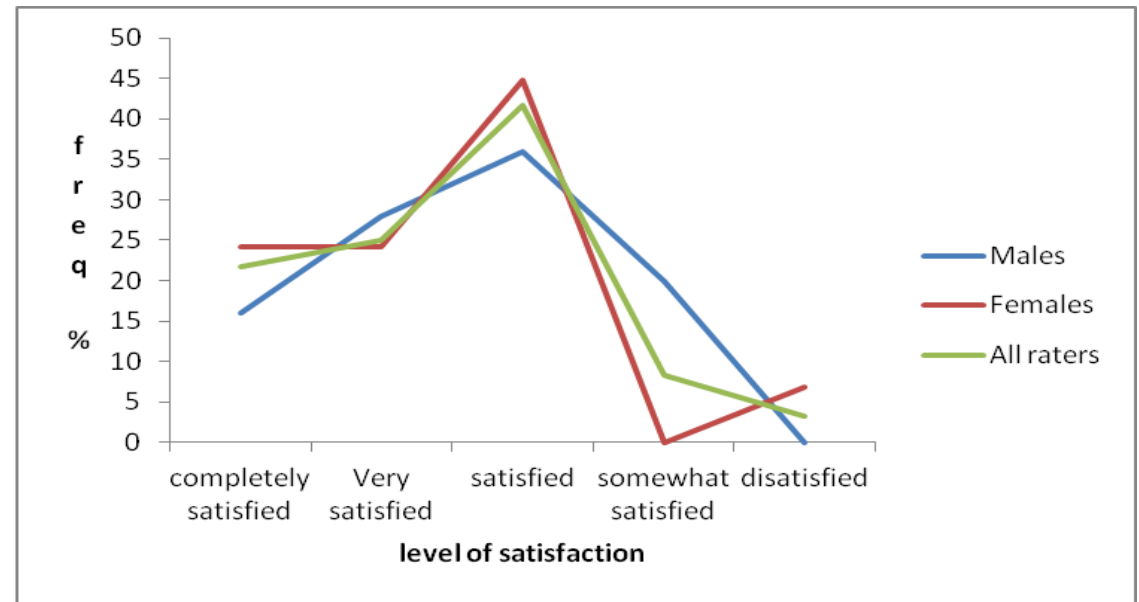

Figure 2: Clients' satisfaction with hospital's performance stratified by sex

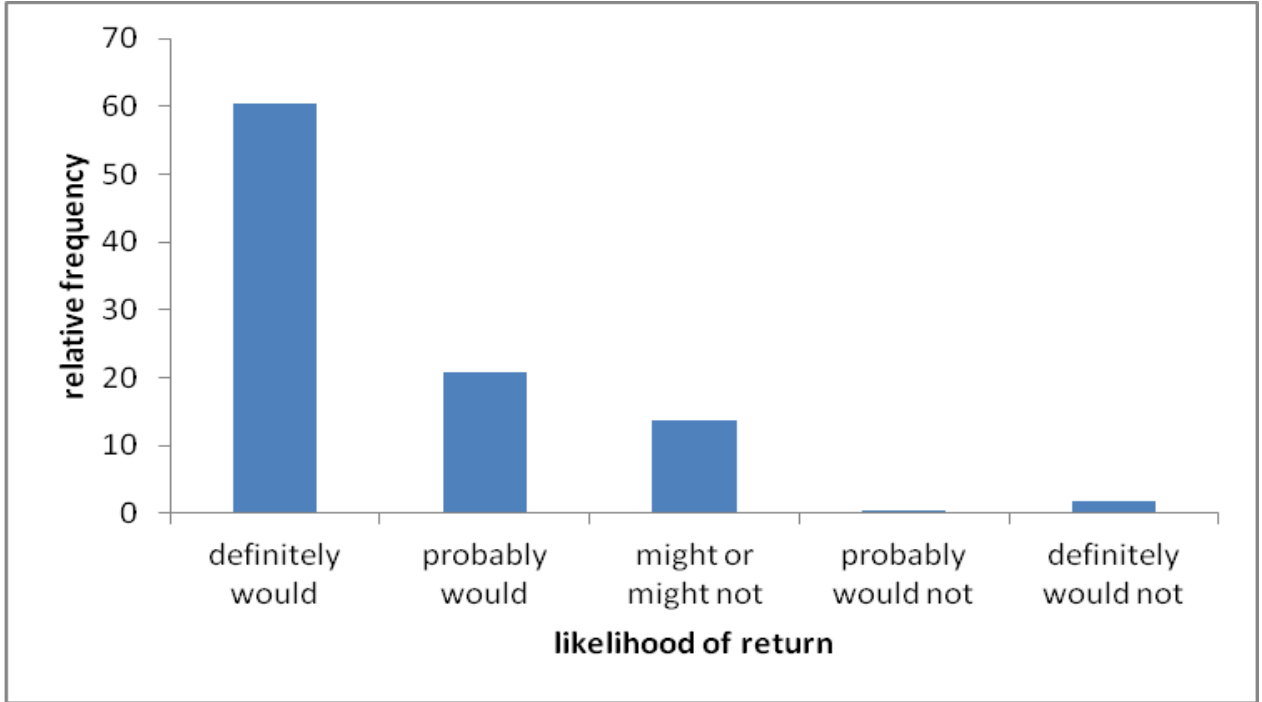

Figure 3: Clients' likelihood of return to same facility in the event of having a similar problem.

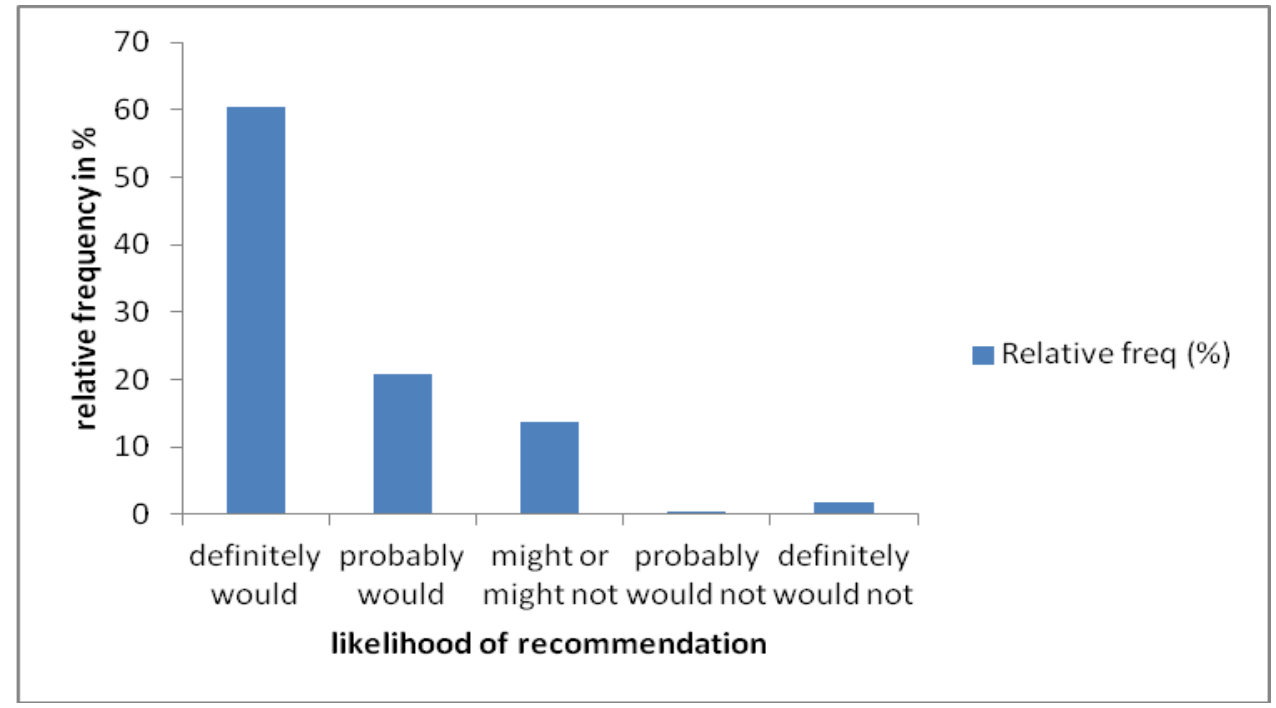

Figure 4: Likelihood of recommending the facility to friends and relatives with similar problems. 